DOI: http://dx.doi.org/10.18569/tempus.v13i3.2646

\title{
A educação permanente e sua influência na micropolítica do trabalho em saúde bucal
}

\section{Continuing education and their influence in micropolicy work in oral health care}

\section{Educación permanente y su influencia en la micropolítica del trabajo de salud oral}

\author{
Wagner Scherrer Lemgruber Goulart ${ }^{1}$ \\ Edson Theodoro dos Santos Neto ${ }^{2}$ \\ Carolina Dutra Degli Esposti ${ }^{3}$
}

RESUMO: A educação permanente em saúde é um movimento que permite produzir processos de formação no próprio espaço de trabalho, promovendo reflexões sobre como tem se materializado as ações de saúde, com vistas a problematizá-las e reconstruí-las por meio de práticas educativas significativas. Este artigo objetiva analisar a percepção de cirurgiões-dentistas e de coordenadores municipais de saúde bucal sobre as repercussões micropolíticas da Política Nacional de Educação Permanente em Saúde (PNEPS) implementada numa região do Espírito Santo, Brasil. Trata-se de uma pesquisa qualitativa, cuja construção dos dados deu-se a partir de um grupo focal. A discussão do grupo focal foi gravada, transcrita e foi submetida a uma análise de conteúdo temática, processada no programa Maxqda 12.0. Os resultados apontaram as estratégias realizadas e a organização inicial da política implementada, bem como fatores que a facilitaram ou a dificultaram. Percebeuse o efeito da educação permanente em saúde na micropolítica do processo de trabalho das equipes de saúde bucal. Contudo, constatou-se barreiras a serem enfrentadas na gestão, no processo de trabalho clínico-técnico e no controle social. Conclui-se que há necessidade de se promover efetivas oportunidades de crescimento dos profissionais da saúde por meio da valorização da educação permanente em saúde, bem como, o envolvimento de todos os atores sociais.

\footnotetext{
1 Mestre em Clínica Odontológica (UFES) - Cirurgião dentista da Prefeitura Municipal de Domingos Martins, Espírito Santo.

2 Doutor em Epidemiologia em Saúde Pública (ENSP/Fiocruz) - Professor Adjunto do Departamento de Medicina Social e Programa de Pós-Graduação em saúde Coletiva/UFES

3 Doutora em Saúde Pública (ENSP/Fiocruz) - Professora Adjunta do Departamento de Medicina Social e Programa de Pós-Graduação em saúde Coletiva/UFES
} 
Palavras-chave: Políticas públicas de Saúde; Educação Permanente; Capacitação de recursos humanos em saúde.

ABSTRACT: Permanent Health Education is a tool that provide education processes in the workspace, promoting reflections on how healthcare actions are being establlished, their problems and how these actions can be rebuild through significant educational practices. This article aims to analyze dentists and local oral health coordinators impressions of micropolicies repercussions of the National Policy of Continuing Education in Healthcare (PNEPS) implemented in a region of Espírito Santo State, Brazil. This is a qualitative research, which the data was formed by a focus group. The discussion of the focus group was recorded, transcribed and was subjected to content analysis, processed in Maxqda 12.0 software. The results showed the strategies carried out and the initial organization of policy implemented as well positive and negative factors. It was noticed the effect of the Permanent Health Education micropolicy in the oral health teams working process. However it was found some barriers that have to be overcome in the management, the clinical and technical work process and in the social control. It is concluded that there is need to promote effective growth opportunities of health professionals through the enhancement of continuing education in healthcare, as well as the involvement of all social players.

Keywords: Public Health Policy; Permanent education; Health human resource training.

RESUMEN: La educación permanente en salud es un movimiento que permite la producción de procesos de capacitación en el propio espacio de trabajo, promoviendo reflexiones sobre cómo se han materializado las acciones de salud, con el fin de problematizarlas y reconstruirlas a través de prácticas educativas significativas. Este artículo tiene como objetivo analizar la percepción de los cirujanos dentales y los coordinadores municipales de salud oral sobre las repercusiones micropolíticas de la Política Nacional de Educación Permanente en Salud (PNEPS) implementada en una región de Espírito Santo, Brasil. Esta es una investigación cualitativa, cuya construcción de datos se basó en un grupo focal. La discusión del grupo focal fue grabada, transcrita y sometida a un análisis de contenido temático procesado en el programa Maxqda 12.0. Los resultados señalaron las estrategias realizadas y la organización inicial de la política implementada, así como los factores que la facilitaron u obstaculizaron. Se notó el efecto de la educación permanente en salud sobre la micropolítica del proceso de trabajo de los equipos de salud oral. Sin embargo, había barreras que enfrentar en la gestión, el proceso de trabajo clínico-técnico y el control social. Se concluye que existe la necesidad de promover oportunidades de crecimiento efectivas para los profesionales de la salud a través de la valoración de la educación permanente en salud, así como la participación de todos los actores sociales.

Palabras-clave: Políticas Públicas de Salud; Educación Continua; Capacitación de Recursos Humanos en Salud 


\section{INTRODUÇÃO}

A Atenção Primária à Saúde (APS) é a porta de entrada no sistema de serviços de saúde e o locus de responsabilidade pela atenção aos pacientes e às populações no decorrer do tempo ${ }^{1}$. Trata-se de uma estratégia de organização do Sistema Único de Saúde (SUS), a qual atua como protagonista na construção das políticas orientadoras da formação, desenvolvimento, distribuição, regulação e gestão dos profissionais de saúde, tendo fortificado sua preocupação com a lógica da saúde individual e coletiva prestada aos usuários ${ }^{2}$. Em 2004, o Ministério da Saúde do Brasil instituiu a Política Nacional de Educação Permanente em Saúde (PNEPS), com a finalidade de formar e capacitar profissionais da saúde para atenderem às reais necessidades da população, conforme os princípios do SUS². Em 2007, novas diretrizes e estratégias para a implementação da PNEPS foram criadas, reafirmando os princípios da educação permanente em saúde (EPS) como norteadores para a construção dos planos regionais de saúde e das ações educativas na saúde 3 .

Educar 'no' e 'para o' trabalho é o pressuposto da EPS e os lugares de produção de cuidado, visando integralidade, corresponsabilidade e resolutividade, são, ao mesmo tempo, cenários de produção pedagógica, pois concentram o encontro criativo entre trabalhadores e usuários ${ }^{4}$. A EPS propõe que, por meio da análise coletiva dos processos de trabalho em saúde, os atores envolvidos possam se responsabilizar mutuamente pela produção de autonomia e de cuidados na perspectiva da integralidade da assistência ${ }^{5}$.

O processo de trabalho é um jogo entre produção, consumo e necessidades dos indivíduos e, na área da saúde, de forma muito específica, produz atos de saúde que perseguem a produção do cuidado. O conceito de 'processo de trabalho em saúde', dessa forma, diz respeito à dinâmica interna do trabalho em saúde, à dimensão 'micro' do cotidiano do trabalho, referente à prática dos trabalhadores/profissionais de saúde inseridos no dia-a-dia da produção e consumo de serviços de saúde $^{6}$. É no mundo do trabalho, na micropolítica, que se determina o modo de operar os modelos de atenção em saúde, tendo como objeto central a produção do cuidado, que pressupõe a frequente presença do trabalho vivo, a sustentar o princípio da integralidade da assistência ${ }^{7}$. Sendo assim, a EPS opera na micropolítica do processo de trabalho e, nesse sentido, envolve o nível molar (macropolítico) e molecular (micropolítico) não como opositores, mas como expressão do cotidiano de políticas, economias, desejos e formas de andar a vida ${ }^{8}$.

A EPS também propõe, baseada na aprendizagem significativa, que a análise coletiva dos processos de trabalho seja desenvolvida na interlocução, em rodas de conversas sobre os problemas e as dificuldades vivenciadas no cotidiano da produção do cuidado, da gestão, da formação dos trabalhadores para o SUS e da participação e controle social ${ }^{5}$.

Problematizar a realidade é importante, pois pode despertar no sujeito a sensação de incômodo e a percepção de que sua prática não está respondendo às necessidades de saúde das pessoas. Segundo esses autores, esse incômodo só pode ser despertado quando ele é percebido, vivido de 
forma intensa. A vivência e a reflexão sobre as práticas de trabalho são os caminhos ideais para produzir insatisfações e disposição para elaborar alternativas que visem enfrentar os desafios ${ }^{8}$.

A EPS aponta para a importância dos trabalhadores se envolverem como protagonistas efetivos no processo de implementação da PNEPS, deixando a condição de recursos para o estatuto de atores sociais das reformas, do trabalho, das lutas pelo direito à saúde e do ordenamento de práticas acolhedoras e resolutivas de gestão e de atenção à saúde?

No contexto das equipes multiprofissionais de saúde no SUS, a existência de equipes de saúde bucal permanentemente integradas e capacitadas também por meio da EPS, além de trazer benefícios internos à própria instituição, também traz benefícios à comunidade, tais como: a ampliação de acesso; a assistência de qualidade; e a prática de uma Odontologia mais social ${ }^{10}$. Percebendo a importância das práticas de EPS nos serviços, torna-se fundamental realizar avaliações que busquem compreender como a PNEPS vem sendo incorporada no cotidiano das práticas de cuidado em saúde no SUS, também com relação às equipes de saúde bucal na APS.

Diante dessas considerações iniciais, o objetivo deste trabalho foi analisar a percepção de cirurgiões-dentistas e de coordenadores municipais de saúde bucal sobre a micropolítica da PNEPS implementada para equipes de saúde bucal da APS na Região Metropolitana da Grande Vitória, Espírito Santo, Brasil, entre os anos de 2007 e 2012.

\section{PERCURSO METODOLÓGICO}

Trata-se de um estudo descritivo com abordagem qualitativa. Este tipo de estudo, segundo Minayo $^{11}$, é caracterizado por permitir ao pesquisador analisar e descrever mais detalhadamente os dados coletados, além de tornar possível a incorporação de questões acerca do significado e da intencionalidade, como sendo inerentes aos atos produzidos, às relações existentes e às estruturas sociais e também desvelar processos sociais ainda pouco conhecidos, referentes a grupos particulares.

Para a seleção dos sujeitos de pesquisa, utilizou-se o seguinte critério: ter atuado como cirurgiãodentista na APS e/ou coordenador municipal de saúde bucal em um dos sete municípios da Região Metropolitana da Grande Vitória - Espírito Santo (RMGV-ES) no período entre 2007 e 2012. Foi realizado um primeiro contato, por telefone, com todos os 33 profissionais informados pelas prefeituras como aqueles que atendiam ao critério de seleção. Desses, somente 16 profissionais aceitaram participar da pesquisa. Foi solicitado aos participantes que levassem no dia do encontro, durante o qual os dados seriam construídos, os certificados e os comprovantes de atividades de Educação Permanente referentes ao período de 2007 a 2012, no intuito de fazê-los rememorar o período vivido nos serviços de saúde.

Os dados foram construídos por meio de um grupo focal, no mês de junho de 2015, num auditório da Universidade Federal do Espírito Santo, em horário de final de expediente. A escolha 
dessa técnica de coleta de dados relacionou-se ao entendimento de que a EPS é um processo de construção coletiva e que, por meio do grupo focal, é possível delinear as etapas que favorecem a elaboração dialética do pensamento grupal com vistas à construção coletiva do conhecimento sobre a temática, conforme destacado por Aschidamini; Saupe ${ }^{12}$. Apesar da confirmação prévia da presença de todos os 16 convidados, os representantes dos municípios de Guarapari e de Fundão não compareceram no dia e no local agendados, por motivos pessoais. Ao todo, participaram do grupo dez sujeitos, representantes dos municípios de Serra, Vitória, Cariacica, Vila Velha e Viana. A integração inicial entre os participantes aconteceu por meio de uma recepção com um lanche. Foi realizada a apresentação do grupo de pesquisa, composto por um mediador, dois observadores externos, dois digitadores e três assistentes de gravação de áudio, seguida de uma breve explanação acerca dos objetivos do estudo. Todos aqueles que concordaram em participar, realizaram a leitura e a assinatura em duas vias do termo de consentimento livre e esclarecido. Além desse termo, foi entregue a cada um dos participantes uma ficha de identificação para preenchimento de dados sobre idade, sexo, tempo de formação, vínculo empregatício e pós-graduação realizada.

O grupo focal teve a duração aproximada de uma hora e 20 minutos. Ao término do grupo, foi realizada uma reunião entre os pesquisadores, para discussão e relato sobre os pontos mais relevantes. O debate do grupo focal foi gravado e transcrito na íntegra e de forma literal. Após a leitura do material foram retirados os vícios de linguagem para proteção e não identificação dos participantes da pesquisa.

Esse material empírico do grupo focal foi analisado segundo a Análise de Conteúdo temática, proposta por Bardin ${ }^{13}$, visando captar sentimentos, significados, atitudes e comportamentos que residem nas entrelinhas dos depoimentos, levando os pesquisadores à possibilidade de decifrarem o processo e o desenvolvimento da micropolítica de EPS na RMGV-ES.

A análise do material iniciou-se com o processo de leitura flutuante, quando o pesquisador, sob supervisão, entrou em contato com o conteúdo transcrito da discussão, em busca de elementos relacionados ao processo micropolítico da PNEPS implementada na RMGV-ES, no período de 2007 a 2012. Os sentimentos e os comportamentos que surgiram no decorrer das atividades desenvolvidas, as implicações da PNEPS implementada no processo de trabalho das equipes de saúde bucal e as barreiras enfrentadas pelos profissionais dessas equipes.

Na sequência foi realizada a categorização, utilizando-se como ferramenta o software de análise de dados qualitativos MAXqda 12.0, que visa tornar a análise qualitativa mais precisa, confiável e transparente, sem interferir nas etapas de leitura, categorização e reflexão que continuam sendo realizadas pelo pesquisador ${ }^{14}$.

Atendendo à Resolução n ${ }^{\circ}$ 466/12 do Conselho Nacional de Saúde, o projeto foi encaminhado ao Comitê de Ética em Pesquisa do Centro de Ciências da Saúde da Universidade Federal do Espírito Santo, sob o número de registro (CAAE 38637414.0.0000.5060), obtendo o parecer favorável 
$n^{\circ}$ 959.863 em 23/02/2015. Esse trabalho é um recorte de dissertação de mestrado em Clínica Odontológica da Universidade Federal do Espírito Santo intitulada: A Percepção dos CirurgiõesDentistas da APS sobre a Política Nacional de Educação Permanente em Saúde Implementada na Grande Vitória-ES.

\section{RESULTADOS E DISCUSSÃO}

Dos dez participantes do grupo focal, sete atuaram como cirurgiões-dentistas em equipes de saúde bucal da APS e três como coordenadores municipais de saúde bucal na RMGV-ES, no período de 2007 a 2012. Destaca-se que todos participantes possuíam pós-graduação em nível de especialização, um possuía também mestrado e outro mestrado e doutorado. Suas idades variaram entre 34 e 61 anos; seis eram do sexo feminino; o tempo de formação versou entre 11 e 39 anos; oito graduaram-se no estado do Espírito Santo, um em Minas Gerais e um no Rio de Janeiro; e nove possuíam vínculo empregatício efetivo no momento da coleta dos dados.

A partir das sucessivas leituras da transcrição do grupo focal, emergiram categorias e subcategorias que foram organizadas em um quadro para análise e discussão. Neste trabalho, serão apresentadas as seguintes categorias: 1. Trajetória da PNEPS implementada para a Equipe de Saúde Bucal na APS e 2. Implicações da PNEPS no processo de trabalho em saúde bucal na APS. Compreendese que essas categorias tangenciam a abordagem das intervenções em saúde pública em seu nível micropolítico, entendido como "o plano molecular em que se efetuam os processos de subjetivação a partir das relações de poder" ${ }^{\prime 15}$. A construção temática dos resultados, conforme categorias, será apresentada a seguir.

\section{Categoria 1: Trajetória da PNEPS implementada na perspectiva da Equipe de Saúde Bucal da APS}

O início do processo de implementação da PNEPS na região em estudo, de acordo com os participantes do grupo focal, ocorreu com a criação de uma comissão local de educação permanente, seguida da formação de facilitadores de educação permanente e da elaboração e execução de diversos cursos multiprofissionais. As capacitações na área da saúde devem ser consideradas estratégicas para a consolidação do SUS, podendo constituir-se num espaço concreto de construção de competências técnica, política e ética para o fortalecimento dos recursos humanos. Os trechos abaixo destacam o início da política:

"a primeira coisa que aconteceu no momento que eu estava lá foi a instituição da comissão de educação permanente [...] eu consegui participar ativamente foi da formação dos profissionais para tutoria, para desenvolver o processo da educação permanente"

"foram ofertados inúmeros cursos tanto para odontologia quanto para todos os profissionais da rede vários cursos: fitoterapia; especialização em saúde coletiva; de 
saúde da família"

O Ministério da Saúde adotou a EPS como conceito pedagógico para desenvolver relações orgânicas entre o ensino e as ações e serviços de atenção à saúde, apostando-se na capacidade de articulação e organicidade da PNEPS, entendendo a EPS como eixo estruturante do processo ${ }^{2}$. A PNEPS deve considerar as necessidades de formação e de desenvolvimento para o trabalho em saúde e a capacidade já instalada de oferta institucional de ações formais de educação na saúde Como uma das estratégias para alimentação da PNEPS, o Ministério da Saúde desencadeou um amplo processo de formação de facilitadores da EPS, com o objetivo de ampliar, no menor tempo possível, o número de pessoas capazes de operar e fortalecer a PNEPS em todo o país ${ }^{16}$. Também foram promovidos diferentes tipos de atividades de formação dos trabalhadores da rede de serviços e das instituições de ensino como: formação de tutores/facilitadores/orientadores para a EPS nas áreas de gestão e atenção à saúde; especialização em saúde da família; e atualização e desenvolvimento em áreas temáticas prioritárias (incluindo aspectos da clínica e da saúde coletiva) ${ }^{2}$. Dessa forma, torna-se fundamental apresentar estratégias que visem gerar processos de trabalho eficientes, com capacidade de gerar produção de saúde de forma integral, universal e equânime.

Os participantes do grupo focal também apontaram que, dentre as estratégias realizadas, foi desenvolvida a dinâmica da roda de EPS. A educação por meio da roda possibilitou ao grupo que fossem realizadas reflexões e discussões sobre as problemáticas e as necessidades enfrentadas no cotidiano do serviço. Essa percepção pode ser exemplificada nos seguintes trechos da discussão:

"uma roda, uma vez por semana, meio período de educação permanente [...] e a gente fazia uma roda para discutir as questões"

"nas unidades de saúde, tinha as rodas de educação permanente, nós tínhamos esse espaço garantido”

Nessa relação entre ensino e sistema de saúde, sai a arquitetura do organograma para entrar a dinâmica da roda. A noção de gestão colegiada coloca a todos como participantes de uma operação conjunta, que usufruem do protagonismo e da produção coletiva ${ }^{17}$, 2004a). Segundo Ceccim ${ }^{9}$, a EPS é uma ação pedagógica que, ao tomar como foco o cotidiano do trabalho, possibilita a construção de processos de autoanálise, no qual diferentes atores, ao serem colocados em roda, conseguem assumir papéis pró-ativos na condução dos sistemas locais de saúde. Desse modo, as rodas de conversa são um meio indispensável e essencial de conscientização capaz de transformar de forma radical as ações laborais frente à vida. Considera-se que a EPS não se caracteriza por apresentar algo novo, mas, sim, fazer relembrar o que está guardado na memória e reavaliar e modificar as ações a partir dessa análise.

Entende-se, assim, que o método da roda é uma proposta para romper com o modelo hegemônico de gestão baseado no escasso debate em torno da atenção integral e desenvolver o exercício da co- 
gestão, por meio da criação de espaços coletivos que ampliem a capacidade e a possibilidade dos sujeitos de analisar, definir tarefas e elaborar projetos de intervenção na realidade. Isso se torna importante na medida em que espaços coletivos de reflexão sobre as práticas de saúde, aproxima os diferentes membros da equipe de saúde bucal e dessa com a comunidade.

Entretanto, na percepção de cirurgiões-dentistas e de coordenadores municipais de saúde bucal, a organização inicial da PNEPS implementada na RMGV-ES foi realizada de uma forma vagarosa:

"eu acho que como todo o município, a implantação do processo, foi assim bem devagar, todo mundo um pouco receoso"

"eu acho que ainda, está engatinhando, precisa ouvir mais o pessoal que está na ponta para saber realmente o que a gente está querendo e precisando"

O fator limitante mais expressivo para a implementação da PNEPS relaciona-se ao distanciamento entre os gestores e os profissionais de saúde, que nunca ou quase nunca participam do planejamento da gestão ${ }^{18}$. Verifica-se, que a gestão da saúde é constituída por alguns campos de tensões distribuídos em diferentes territórios de disputa, de forma que, inseridos dentro das organizações de saúde, caracterizam espaços marcados pela luta por poder, tomada de decisões e autonomia entre os sujeitos. Também são permeados pela configuração de práticas estruturadas pela disputa de interesses e pela capacidade de agir, e pela produção de atos de saúde, marcados pela micropolítica do trabalho vivo em ato, e pelos autogovernos dos trabalhadores da saúde ${ }^{8}$. Sendo assim, o apoio e o incentivo da gestão são de extrema importância para o desenvolvimento da proposta pedagógica da EPS, visto que essa é uma ferramenta que requer reflexão crítica do profissional. Se não houver um gestor sensibilizado com a proposta, podem haver conflitos que impeçam uma ação sólida com resultados efetivos.

Salientou-se também, durante o grupo focal, que a PNEPS tem por finalidade a formação e capacitação dos profissionais de saúde para atenderem às reais necessidades de saúde da população. Infere-se que a criação de Escolas Técnicas do SUS representaram a institucionalização de um espaço físico para o desenvolvimento das atividades da PNEPS pelos profissionais de saúde. Tal entendimento pode ser observado nos trechos de discussão destacados abaixo:

"a criação da escola é algo muito bom, tem uma estrutura física muito boa"

“a implantação da escola e dos cursos trouxe muitos benefícios, porque muitos profissionais foram capacitados, inclusive profissionais que não eram efetivos"

"teve oficinas: de endodontia, de cirurgia, de enfim, de todas as especialidades que o centro de especialidade oferta"

A PNEPS propõe a reestruturação dos serviços, a partir do cotidiano de trabalho, tendo o 
profissional como sujeito central do processo de ensino-aprendizagem ${ }^{19}$. Tal política ainda tem como objetivo promover uma mudança institucional no sentido de fortalecer as ações em equipe e transformar práticas técnicas e sociais. Isso implica em uma pedagogia centrada na resolução de problemas e efetuada no ambiente de trabalho, de maneira a promover a apropriação do saber científico, configurando-se como responsabilidade da instituição na qual o profissional atua ${ }^{20}$. Porém ressalta-se que a perspectiva dos sujeitos da pesquisa, com relação aos cursos e capacitações, em parte, parece distanciar-se dos pressupostos da EPS, pois apontam os processos de formação como uma garantia de atualização das técnicas/conteúdos do trabalho em saúde, de forma fragmentada, que se aproximariam mais da proposta de Educação Continuada.

Apesar da EPS propor relações democráticas e de estímulo à participação de todos os sujeitos, na discussão do grupo focal, com relação aos fatores que dificultaram a implementação da PNEPS, os participantes revelaram sentimentos de falta de governabilidade no planejamento das ações junto à gestão. Isso foi evidenciado como fator negativo:

"a gente não tinha essa governabilidade nem de qual curso nem de quem iria fazer esse curso"

"era e ainda é um planejamento muito da gestão para gente, e não da gente pra gestão [...] muitas vezes era um planejamento que não se encaixava na nossa realidade"

"vem deles para gente, não é o que a gente está pedindo"

No setor da saúde, tem se caracterizado pela realização de capacitações pontuais, na sua maioria de caráter programático e centralizado, com conteúdo padronizado, desenvolvidos a partir de uma lógica vertical e programática. Esse processo aumentou a frustração dos profissionais que, ao retornarem aos seus serviços, não conseguem aplicar o que aprenderam ou constatam que o que aprenderam não lhes fornece elementos suficientes para enfrentar as problemáticas da realidade concreta $^{21}$. Segundo Merhy ${ }^{6}$, no Brasil, há necessidade de práticas gerenciais libertárias e inovadoras que possibilitem ao trabalhador, contextualizado na micropolítica do trabalho vivo em saúde, a oportunidade para ver/ouvir/sentir o processo de trabalho.

Há um grande novo desafio: produzir auto-interrogação no agir produtor do cuidado e colocar-se ético-politicamente em discussão, no plano individual e coletivo do trabalho ${ }^{22}$. A PNEPS propõe que os processos de capacitação dos trabalhadores da saúde devem tomar como referência as necessidades de saúde das pessoas e das populações, da gestão setorial e do controle social, tenham como objetivos a transformação das práticas profissionais e da própria organização do trabalho e sejam estruturados a partir da problematização do processo de trabalho ${ }^{17}$.

Para mudar essa lógica das estruturas organizacionais da saúde, é preciso acontecerem amplas alterações na organização do trabalho (gestão, profissionais e usuários) e a EPS é uma das ferramentas que pode ser utilizada para que isso aconteça, pois tem a potência de produzir um processo de 
trabalho articulado, horizontal, participativo e dentro das reais necessidades dos trabalhadores e usuários do SUS, permitindo a prática de uma Odontologia mais social.

\section{Categoria 2: Implicações da PNEPS no processo de trabalho em saúde bucal na APS}

Para que a transformação das práticas em saúde ocorra de maneira efetiva é necessário encarar o real valor da educação como meio para o crescimento profissional, contribuindo assim, para a melhoria da assistência à população. É importante ressaltar que o convívio com outras profissões tem justamente como principal objetivo a desestabilização dos modos instituídos, por provocar interlocuções em diferentes áreas de conhecimento, de forma contribuir para um perfil profissional mais flexível que saiba conciliar a atuação específica de cada área com o necessário trabalho coletivo nas instituições de saúde. Essas mudanças, possibilitadas a partir da prática da EPS, foram evidenciadas durante a discussão do grupo focal:

"a gente começou a modificar, o processo de trabalho, que antes era muito centrado nas quatro paredes do consultório e começou a ampliar mais, trabalhar em equipe, com os enfermeiros, com os médicos e participar também da parte de prevenção, promoção de saúde”

"agregar conhecimento é uma questão de você estar encontrando outros profissionais, com outras experiências"

É fundamental a compreensão de que, apesar do trabalho em saúde estar pautado em normas institucionais, cada profissional tem a autonomia de desenvolver o cuidado dentro do espaço micropolítico. O profissional deve ter em mente que cada indivíduo por ele assistido é único e com uma história própria, também única, não cabendo normas ou formas rígidas de atendimento. Deve considerar, ainda, que uma equipe é composta por pessoas que trazem particularidades e interesses próprios. Essas características exercem influência sobre o processo de trabalho, uma vez que estão presentes no agir cotidiano de cada profissional e portanto, passível de erros e acertos dependendo da forma como são conduzidas ${ }^{23}$. Assim, a troca de saberes e o respeito mútuo às diferentes percepções devem acontecer permanentemente entre todos os profissionais de saúde para possibilitar que aspectos da saúde bucal também sejam devidamente apropriados e se tornem objeto das suas práticas ${ }^{24}$. Acrescenta-se a isso o fato de que atender, por meio do trabalho em equipe, às necessidades dos usuários dos serviços de saúde, respeitando os princípios do SUS, buscando-se alcançar a equidade e a integralidade da atenção, gera a possibilidade de, para além do aumento de cobertura das ações, tornar os resultados mais ricos, produtivos e resolutivos.

No entanto, durante a discussão do grupo focal, os integrantes também apontaram algumas barreiras para a efetivação da PNEPS implementadas para as equipes de saúde bucal envolvidas na APS. Um dos fatores destacados foi a frequente priorização dada pelos gestores à produtividade, em detrimento da qualidade da assistência a ser prestada pelos profissionais à população, bem 
como, a dificuldade em se colocar em prática os conhecimentos adquiridos, pelo foco na produção, como evidenciado nos seguintes trechos da discussão:

"o tempo todo a gestão te pede tudo! Você tem que ser o melhor na restauração, no menor tempo possível, com o pior material que tiver. Tem que fazer tudo com nada e assim não funciona"

"a gente agrega muito conhecimento, mas enquanto a flexibilidade de aplicar, na real, quase nenhuma! Porque às vezes a gente escuta uma coisa que não tem espaço para fazer"

Para que os profissionais de saúde ocupem um lugar ativo na EPS, é necessário que adquiram novas habilidades, rompam com os modelos hegemônicos de produção e superem as modelagens de serviços centrados em procedimentos para configurar novas produções ${ }^{9}$. No entanto, existem dificuldades de agregar melhorias para os serviços discutidas durante o processo educativo, mantendo-se a reprodução de práticas isoladas e mecânicas que, na maior parte das vezes, não se ajustam à realidade locorregiona $2^{25}$. Isso ocorre, talvez, em decorrência do receio de tornar o serviço um espaço democrático de análise crítica e opinião coletiva e pela insegurança política ou de saberes, que impossibilita o avanço e/ou ampliação da PNEPS implementada neste cenário, dificultando a reorganização do sistema de saúde e a efetiva participação dos atores.

A construção das competências do cirurgião-dentista para atuar na APS em saúde aponta para a valorização de um novo perfil profissional, inserido em abordagens tanto individuais quanto coletivas, em consonância com um movimento social amplo e cujas principais consequências, refletem-se nos mundos do trabalho e da educação. A falta desse perfil profissional também foi apontada como barreira para a efetivação das implicações que se esperava segundo proposta da PNEPS, como segue:

"falta de perfil profissional, algumas pessoas que estão na saúde pública, também não estão preocupadas com o processo de trabalho: só atender, acabar e ir embora"

Historicamente, o cirurgião-dentista recebeu uma educação voltada para os aspectos biológicos e para as ações curativas e técnicas, com pouca ênfase sobre os fatores socioeconômicos e psicológicos que interferem no processo saúde-doença e no desenvolvimento de atividades de promoção, de manutenção e de recuperação da saúde ${ }^{26}$. Nesse sentido, as universidades devem cumprir seu papel de trabalhar em função de uma formação profissional cujo perfil atenda às necessidades da população em todos os níveis de atenção e ao longo dos seus processos sócio-vitais, afinal, é notável que a formação em saúde afeta profundamente a qualidade dos serviços e o grau de satisfação dos usuários $^{27}$. Para isso, as instituições de ensino devem garantir uma aprendizagem, na qual o aluno vivencie seu percurso produtivo, evitando formar profissionais alienados, preocupados somente com suas competências específicas sem colocá-las a serviço de um projeto integral, na lógica do trabalho em equipe ${ }^{28}$. O documento que trata das Diretrizes Curriculares Nacionais dos Cursos 
de Graduação em Odontologia, entende como competência específica a ser desenvolvida junto ao estudante de graduação a atuação multiprofissional, interdisciplinar e transdisciplinar com extrema produtividade na promoção da saúde, baseado na convicção científica, de cidadania e de ética ${ }^{29}$. Pode-se, assim, compreender que as competências requeridas para o trabalho do cirurgião-dentista na APS se constituem e são indispensáveis, para possibilitar o suporte necessário para a construção do SUS, sendo que essas competências devem atender às necessidades de articulação da prática e da formação do cirurgião-dentista, em uma perspectiva do cuidado à saúde e da responsabilidade social.

Por fim, discutiu-se que, embora o controle social seja um dos preceitos do SUS e objeto de investimento do processo de EPS, seu desenvolvimento, na região do estudo, não foi percebido pelos participantes do grupo focal, tendo sido apontado como uma das dificuldades da PNEPS implementada na RMGV-ES. Essa percepção pode ser exemplificada no seguinte trecho da discussão:

"Não tem nenhum controle social, lá dentro da comissão [comissão permanente de integração ensino e serviço] principalmente não tem"

A EPS integra todos os segmentos de formação, de atenção, de gestão e do controle social na área da saúde, de forma que, a partir desta integração, possa se pensar na produção de saúde. Segundo Ceccim; Feuerwerker ${ }^{5}$, para haver ações efetivas de mudanças nos ambientes de trabalho, os processos de EPS devem ser direcionados a todos os componentes do quadrilátero (trabalhadores de saúde, gestores, usuários e as instituições formadoras), com um entendimento único das políticas de saúde, bem como das diretrizes dos projetos e programas propostos pelo SUS. Nicoletto; Mendonça; et $a l^{30}$ destacaram a importância da participação de todos os atores do quadrilátero da formação, uma vez que o envolvimento de todos os atores produz a riqueza de saberes, oriundos dos processos de troca de experiências, subjetivações e singularidades de cada ator, que em suas posições diferentes propõem novos arranjos e conhecimentos. Sendo assim, o controle social tem grande importância na transformação das práticas e da produção do conhecimento e na promoção da autonomia do sujeito como participante ativo das tomadas de decisões, desenvolvendo compromissos com a inovação da gestão democrática e participativa. Entende-se que sua ausência, por si só, inviabiliza a aplicação dinâmica da roda (todos os atores do quadrilátero de formação) proposta na PNEPS.

\section{CONSIDERAÇÕES FINAIS}

A EPS propõe a reflexão crítica sobre o processo de trabalho, como alicerce do processo de formação da área da saúde, pois as situações vivenciadas pelas equipes no cotidiano do trabalho podem se constituir em experiências de aprendizagem significativas que incidem no atendimento prestado tanto às necessidades individuais quanto as coletivas. Cabe, assim, aos profissionais da saúde o compromisso de interrogar os problemas do processo de trabalho e da lógica micropolítica da produção do cuidado em saúde e problematizar, juntamente com os usuários, com os representantes 
das instituições de ensino e com os gestores essas questões. Contudo, isso vem ocorrendo em um contexto repleto de obstáculos, uma vez que a PNEPS propõe ações que, na maioria das vezes, contrariam aquilo que está estabelecido.

Os cirurgiões-dentistas e coordenadores municipais de saúde bucal destacam, na trajetória de implementação da PNEPS na APS na RMGV-ES, a criação da comissão local de educação permanente, seguida da formação de facilitadores de educação permanente e da elaboração e realização de diversos cursos multiprofissionais, desencadeando o convívio com outras profissões e contribuindo, assim, como efeito no processo de trabalho e no desenvolvimento de um perfil profissional mais flexível. Também destacaram a realização de reflexões e de discussões sobre as problemáticas e as necessidades vivenciadas no dia-a-dia, possíveis a partir de sua participação nas dinâmicas de roda.

Entretanto, a organização inicial da PNEPS implementada na RMGV-ES foi realizada de uma forma vagarosa e os participantes revelaram sentimentos de falta de governabilidade e planejamento das ações. Também afirmaram que ainda persistem barreiras à efetivação da micropolítica de EPS, destacando como principais pontos a serem enfrentados e superados: a frequente priorização, pelos gestores, à produtividade; dificuldade de se colocar em prática os conhecimentos adquiridos; perfil inadequado da grande maioria dos profissionais atuantes no SUS; e a falta de controle social.

Em relação à produção de conhecimento sobre a micropolítica da EPS implementada para as equipes de saúde, em especial para as equipes de saúde bucal da APS, entende-se que este trabalho não teve por objetivo esgotar a temática, principalmente devido à complexidade do objeto estudado. É possível que novas elaborações, com olhares e métodos diferenciados, possam ser realizadas a fim de aprofundar e discutir sobre a avaliação da PNEPS implementada nas várias regiões brasileiras, entendida enquanto micropolítica de transformação social.

\section{Agência de fomento}

Fundação de Amparo à Pesquisa e Inovação do Espírito Santo (FAPES) - EDITAL nº 006/2014 - UNIVERSAL - PROJETO INDIVIDUAL DE PESQUISA

\section{REFERÊNCIAS BIBLIOGRÁFICAS}

1- Starfield B. Atenção primária: equilíbrio entre necessidades de saúde, serviços e tecnologia. Brasília: UNESCO/ Ministério da Saúde; 2002.

2- Brasil. Ministério da Saúde. Portaria n. ${ }^{\circ}$ 198/ GM/MS, de 13 de Fevereiro de 2004. Institui a Política Nacional de Educação Permanente em Saúde como estratégia do SUS para a formação e o desenvolvimento de trabalhadores para o setor e dá outras providências. Brasília: Ministério da Saúde; 2004. 
3- Brasil, Ministério da Saúde. Portaria n. ${ }^{\circ}$ 1996/GM/MS, de 20 de agosto de 2007. Dispõe sobre as diretrizes para a implementação da política nacional de educação Permanente em Saúde e dá outras providências. Brasília: Ministério da Saúde; 2007.

4- Franco TB. Produção do cuidado e produção pedagógica: integração de cenários do sistema de saúde no Brasil. Botucatu: Revista Interface - Saúde, Educação e Comunicação 2007; 11(23): 427-38.

5- Ceccim RB, Feuerwerker LCM. O quadrilátero da formação para a área da saúde: ensino, gestão, atenção e controle social. Rio de Janeiro: Physis 2004; 14(1):41-65.

6- Merhy EE. Em busca do tempo perdido: a micropolítica do trabalho vivo em saúde. In: Merhy EE e Onocko R, organizadores. Agir em Saúde. Um desafio para o público. São Paulo: Hucitec; 1997. p. 74-111.

7- Merhy EE, FRANCO TB. Por uma composição técnica do trabalho centrado no campo relacional e nas tecnologias leves. Rio de Janeiro: Revista Saúde em Debate 2003; 27(65):31623.

8- Merhy EE, Feuerwerker LCM, Ceccim RB. Educación Permanente en Salud: una estrategia para intervenir en la micropolítica del trabajo en salud. Salud coletiva 2006; 2(2):147-60.

9- Ceccim RB. Educação permanente: desafio ambicioso e necessário. Interface Comun Saúde Educ 2004 set- 2005 fev; 18(9): 161-77.

10- Nunes MF, Pereira MF, Alves RT, Leles CR. A proposta da educação permanente em saúde na formação de cirurgiões-dentistas em DST/HIV/Aids. Botucatu: Revista Interface Comunicação, Saúde, Educação 2008; 12(25):413-20.

11- Minayo MCS. O desafio do conhecimento. Pesquisa qualitativa em saúde. $14^{\mathrm{a}}$ ed. São Paulo: Hucitec; 2014.

12- Aschidamini IM, Saupe R. Grupo Focal - Estratégia metodológica qualitativa: um ensaio teórico. Curitiba: Revista Cogitare Enfermagem 2004; 9(1):9-14.

13- Bardin L. Análise de conteúdo. Lisboa: Edições 70; 2011.

14- Gibbs G. Análise de dados qualitativos. Porto Alegre: Artmed, 2009. p.198.

15- Feuerwerker LCM. Micropolítica e saúde: produção do cuidado, gestão e formação. Porto Alegre: Rede UNIDA; 2014.

16- Brasil. Ministério da Saúde. Secretaria de Gestão do Trabalho e da Educação na Saúde. 
Curso de Formação dos Facilitadores de Educação Permanente em Saúde. Brasília; 2004.

17- Ministério da Saúde. Secretaria de Gestão do Trabalho e da Educação na Saúde. Departamento de Gestão da Educação na Saúde (BR). Política de Educação e Desenvolvimento para o SUS: caminhos para a educação permanente em saúde - Pólos de educação permanente em saúde. Brasília (DF): Ministério da Saúde; 2004. 66p. (Série C. Projetos, Programas e Relatórios).

18- Miccas FL, Batista SHSS. Educação permanente em saúde: metassíntese. São Paulo: Revista de Saúde Pública 2014; 48(1):170-85.

19- Ribeiro ECO, Motta JIJ. Educação Permanente como estratégia na reorganização dos serviços de saúde. Londrina: Revista Divulgação em Saúde para Debate 1996; 12(1):39-44.

20- Ceccim RB. Educação Permanente em Saúde: descentralização e disseminação de capacidade pedagógica na saúde. Ciênc saúde coletiva 2005; 10(4): 975-86.

21- Brasil. Ministério da Saúde. Secretaria de Gestão do Trabalho e da Educação na Saúde. Caminhos para a mudança da formação e desenvolvimento dos profissionais de saúde: diretrizes para a ação política para assegurar educação permanente no SUS. Brasília: Ministério da Saúde; 2003.

22- Merhy EE. O desafio que a educação permanente tem em si: a pedagogia da implicação. Botucatu: Revista Interface - comunicação, saúde, educação 2005; 9(16):161-77.

23- Costa RM, Junior AM, Costa ICC, Pinheiro IVA. O trabalho em equipe desenvolvido pelo cirurgião-dentista na Estratégia Saúde da Família: expectativas, desafios e precariedades. Rio de Janeiro: Revista Brasileira de Medicina de Família e Comunidade 2012;7(24):147-63.

24- Brasil. Ministério da Saúde. Secretaria de Gestão do Trabalho e da Educação na Saúde. Departamento de Gestão da Educação na Saúde. A educação permanente entra na roda: pólos de educação permanente em saúde: conceitos e caminhos a percorrer. Departamento de Gestão da Educação na Saúde. 2a ed. Brasília: Ministério da Saúde; 2005.

25- Nicoletto SCS, Almeida DCS, Brevilheri ECL, Mendonça FF, Rezende LR, Carvalho VLR. Desafios na implantação, desenvolvimento e sustentabilidade da Política de Educação Permanente em Saúde no Paraná, Brasil. São Paulo: Revista Saúde e Sociedade 2013; 22(4):1094-105.

26- Araújo YP, Dimenstein M. Estrutura e organização do trabalho do cirurgião-dentista no PSF de municípios do Rio Grande do Norte. Rio de Janeiro: Revista Ciência \& Saúde Coletiva 2006; 11(1):219-27.

27- Cotta RMM, Schott M, Azeredo CM, Franceschini SCC, Priore SE, Dias G. Organização ISSN 1982-8829 Tempus, actas de saúde colet, Brasília, 13(3),107-122, set, 2019. Epub Jul/2020 
$122 / /$

do trabalho e perfil dos profissionais do programa saúde da família: um desafio na reestruturação da APS em saúde. Brasilia: Revista Epidemiologia e Serviços de Saúde 2006; 15(3):7-18.

28- Merhy EE. Saúde: a cartografia do trabalho vivo. São Paulo: Hucitec, 2002.189 p.

29- Brasil. Resolução nº 3 de 2002. Diário Oficial da União 2002; 04 mar

30- Nicoletto SCS, Mendonça FF, Bueno VLRC, Brevilheri ECL, Almeida DCS, Rezende LR, et al. Pólos de Educação Permanente em Saúde: uma análise da vivência dos atores sociais no norte do Paraná. Interface comun saúde educ 2009; 13(30):209-19.O rá

Artigo apresentado em outubro de 2019 Artigo aprovado em janeiro de 2020 Artigo publicado em julho de 2020 